\title{
Erratum to: Early effects of gastric bypass on endothelial function, inflammation, and cardiovascular risk in obese patients
}

\author{
Stacy A. Brethauer • Helen M. Heneghan - Shai Eldar • \\ Patrick Gatmaitan - Hazel Huang • Sangeeta Kashyap • \\ Heather L. Gornik · John P. Kirwan · Philip R. Schauer
}

Published online: 30 April 2011

(C) Springer Science+Business Media, LLC 2011

\section{Erratum to: Surg Endosc}

DOI 10.1007/s00464-011-1620-6

The correct version of Fig. 1 is published here.

The online version of the original article can be found under doi: 10.1007/s00464-011-1620-6.

S. A. Brethauer $(\bowtie) \cdot$ H. M. Heneghan · S. Eldar .

P. Gatmaitan · P. R. Schauer

Bariatric and Metabolic Institute, M61, Cleveland Clinic,

9500 Euclid Avenue, Cleveland, OH 44195, USA

e-mail: brethas@ccf.org

H. Huang · J. P. Kirwan

Department of Pathobiology, Lerner Research Institute,

Cleveland Clinic, Cleveland, OH 44195, USA

\section{S. Kashyap}

Endocrinology and Metabolism Institute, Cleveland Clinic,

Cleveland, OH 44195, USA

\section{H. L. Gornik}

Heart and Vascular Institute, Cleveland Clinic,

Cleveland, OH 44195, USA
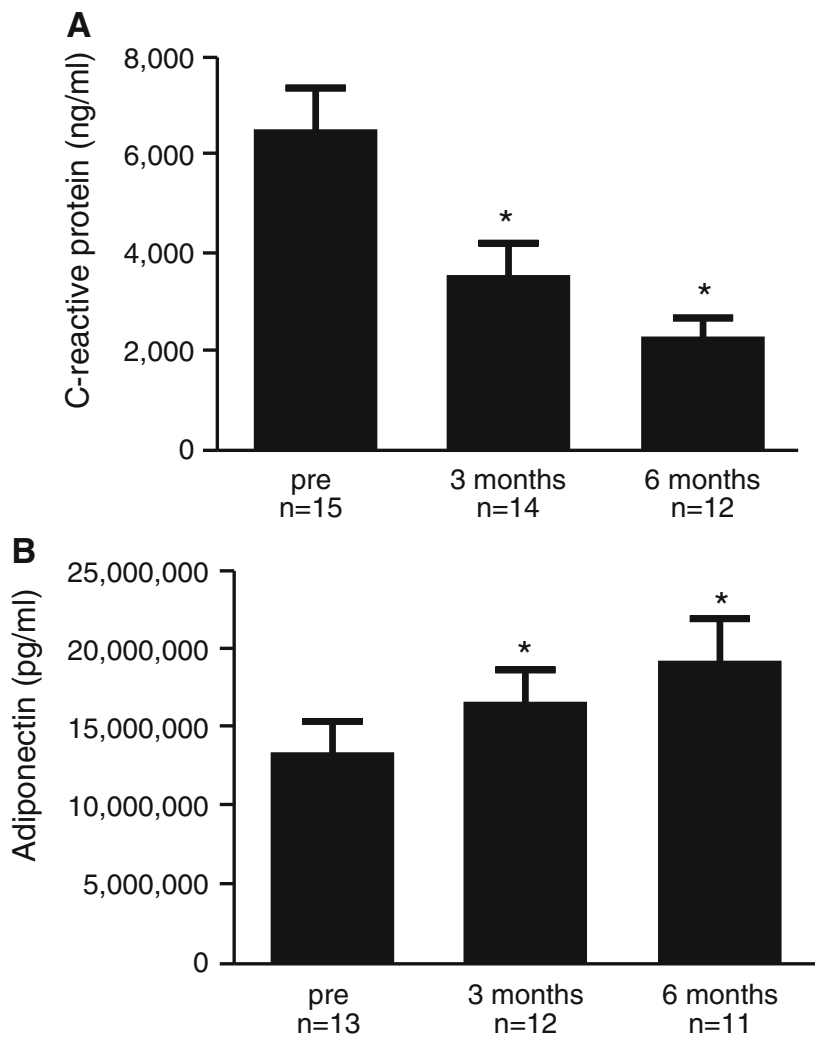

Fig. 1 Changes in adiponectin levels after gastric bypass $(P=0.002$ at 3 months, $P=0.004$ at 6 months). * Statistically significant $(P<0.05)$ compared to baseline level 